\title{
The influence of comorbid anxiety on the effectiveness of Cognitive Therapy and Interpersonal Psychotherapy for Major Depressive Disorder
}

\author{
Citation for published version (APA):
}

van Bronswijk, S. C., Lemmens, L. H. J. M., Huibers, M. J. H., Arntz, A., \& Peeters, F. P. M. L. (2018). The influence of comorbid anxiety on the effectiveness of Cognitive Therapy and Interpersonal Psychotherapy for Major Depressive Disorder. Journal of Affective Disorders, 232, 52-60. https://doi.org/10.1016/j.jad.2018.02.003

Document status and date:

Published: 01/05/2018

DOI:

10.1016/j.jad.2018.02.003

Document Version:

Publisher's PDF, also known as Version of record

\section{Document license:}

Taverne

Please check the document version of this publication:

- A submitted manuscript is the version of the article upon submission and before peer-review. There can be important differences between the submitted version and the official published version of record.

People interested in the research are advised to contact the author for the final version of the publication, or visit the DOI to the publisher's website.

- The final author version and the galley proof are versions of the publication after peer review.

- The final published version features the final layout of the paper including the volume, issue and page numbers.

Link to publication

\footnotetext{
General rights rights.

- You may freely distribute the URL identifying the publication in the public portal. please follow below link for the End User Agreement:

www.umlib.nl/taverne-license

Take down policy

If you believe that this document breaches copyright please contact us at:

repository@maastrichtuniversity.nl

providing details and we will investigate your claim.
}

Copyright and moral rights for the publications made accessible in the public portal are retained by the authors and/or other copyright owners and it is a condition of accessing publications that users recognise and abide by the legal requirements associated with these

- Users may download and print one copy of any publication from the public portal for the purpose of private study or research.

- You may not further distribute the material or use it for any profit-making activity or commercial gain

If the publication is distributed under the terms of Article $25 \mathrm{fa}$ of the Dutch Copyright Act, indicated by the "Taverne" license above, 
Research paper

\title{
The influence of comorbid anxiety on the effectiveness of Cognitive Therapy and Interpersonal Psychotherapy for Major Depressive Disorder
}

\author{
Suzanne C. van Bronswijk ${ }^{\mathrm{a}, \mathrm{b}, *}$, Lotte H.J.M. Lemmens ${ }^{\mathrm{c}}$, Marcus J.H. Huibers ${ }^{\mathrm{d}, \mathrm{e}}$, Arnoud Arntz ${ }^{\mathrm{c}, \mathrm{f}}$, \\ Frenk P.M.L. Peeters ${ }^{\mathrm{a}, \mathrm{b}}$ \\ ${ }^{a}$ Department of Psychiatry and Psychology, Maastricht University Medical Center+, P.O. Box 5800, 6202 AZ Maastricht, The Netherlands \\ ${ }^{\mathrm{b}}$ School for Mental Health and Neuroscience, Faculty of Health, Medicine and Life Sciences, Maastricht University, Maastricht, The Netherlands \\ ${ }^{\mathrm{c}}$ Department of Clinical Psychological Science, Faculty of Psychology and Neuroscience, Maastricht University, Maastricht, The Netherlands \\ ${ }^{\mathrm{d}}$ Department of Clinical Psychology, VU University Amsterdam, Amsterdam, The Netherlands \\ e Department of Psychology, University of Pennsylvania, Philadelphia, PA, USA \\ ${ }^{\mathrm{f}}$ Department of Clinical Psychology, University of Amsterdam, Amsterdam, The Netherlands
}

\section{A R T I C L E I N F O}

\section{Keywords:}

Anxiety disorder

Anxiety symptoms

Cognitive therapy

Interpersonal psychotherapy

Depression

\begin{abstract}
A B S T R A C T
Background: Anxious depression is an important subtype of Major Depressive Disorder (MDD) defined by both syndromal (anxiety disorders) and dimensional (anxiety symptoms) criteria. A debated question is how anxiety affects MDD treatment. This study examined the impact of comorbid anxiety disorders and symptoms on the effectiveness of and dropout during Cognitive Therapy (CT) and Interpersonal Psychotherapy (IPT) for MDD. Methods: Depressed individuals were randomized to CT $(n=76)$ or IPT $(n=75)$. Outcome was depression severity measured with the Beck Depression Inventory-II (BDI-II) at the start of each therapy session, post treatment, and monthly up to five months follow-up. Anxiety disorders were assessed with the Structured Clinical Interview for DSM-IV Axis I disorders, (phobic) anxiety symptoms were assessed with Brief Symptom Inventory subscales.

Results: Approximately one third of participants had a comorbid anxiety disorder. Comorbid anxiety disorders and anxiety symptoms were associated with less favorable depression change during IPT as compared to CT in the treatment phase, but not in the trial follow-up phase. Individuals with a comorbid anxiety disorder had significantly higher treatment dropout during both treatments.

Limitations: Not all therapists and participants were blind to the assessment of comorbid anxiety disorders and the assessments were performed by one rater.

Conclusions: A preference for CT over IPT for MDD is justifiable when comorbid anxiety is present, although long-term differences are not established and replication of this finding is needed. Clinicians should be aware of the risk of dropout for depressed individuals with an anxiety disorder.
\end{abstract}

\section{Introduction}

Given high comorbid anxiety in Major Depressive Disorder (MDD), anxious depression is considered to be an important subtype (American Psychiatric Association, 2013; Rao and Zisook, 2009; Ten Have et al., 2016). This subtype can be defined as MDD with a comorbid anxiety disorder (syndromal definition) or subthreshold comorbid anxiety symptoms (dimensional definition) (Ionescu et al., 2013; Rao and Zisook, 2009). For both definitions, anxious depression has been associated with a severe clinical picture including more severe depressive symptoms (Brown et al., 1996; Fava et al., 2004; Penninx et al., 2011; Smits et al., 2009), more functional impairment (Fava et al., 2004;
Smits et al., 2009) and intensified suicidal thoughts and behavior (Brown et al., 1996; Fava et al., 2004; Fawcett et al., 1990; Pfeiffer et al., 2009). With these profound clinical disadvantages, one could expect an adverse effect of comorbid anxiety on MDD treatment outcome and treatment continuation. However, findings regarding the impact of comorbid anxiety on MDD treatment outcome and dropout are inconsistent for both pharmacotherapy and psychotherapy, and there has been little agreement on tailored treatment recommendations.

Studies examining the effects of antidepressants found that individuals with comorbid anxiety disorders had less favorable outcomes (Howland et al., 2009; Lee et al., 2012) and higher dropout rates (Arnow et al., 2007; Howland et al., 2009). In contrast to anxiety

\footnotetext{
* Corresponding author at: Department of Psychiatry and Psychology, Maastricht University Medical Center+, P.O. Box 5800, 6202 AZ, Maastricht, The Netherlands.

E-mail address: suzanne.vanbronswijk@maastrichtuniversity.nl (S.C. van Bronswijk).
} 
disorders, the impact of comorbid anxiety symptoms on MDD outcome varied from lower response and remission rates (Davidson et al., 2002; Fava et al., 2008; Flint and Rifat, 1997; Frank et al., 2011; Papakostas et al., 2008; Wiethoff et al., 2010) to no adverse effects (Forand and Derubeis, 2013; Fournier et al., 2009; Joffe et al., 1993; Nelson, 2010; Russell et al., 2001; Tollefson et al., 1994). In addition, anxiety symptoms were not associated with dropout in other antidepressant trials (Flint and Rifat, 1997; Fournier et al., 2009; Russell et al., 2001; Tollefson et al., 1994; Wiethoff et al., 2010).

In psychotherapy research, findings on the influence of comorbid anxiety on treatment outcome and continuation are even more inconclusive. Two effective and frequently applied psychotherapies for MDD are Cognitive Therapy (CT) and Interpersonal Psychotherapy (IPT). Most of the psychotherapy studies that examined the impact of comorbid anxiety on MDD outcome focused on CT. Overall, CT studies did not show an adverse effect of anxiety on MDD outcome. Several studies showed similar treatment outcomes for individuals with and without anxiety disorders or with and without anxiety symptoms (Brent et al., 1998; Forand and Derubeis, 2013; Fournier et al., 2009; McEvoy and Nathan, 2007; Persons et al., 2006; Smits et al., 2009). Surprisingly, other CT studies reported a more accelerated depressive symptom improvement when comorbid anxiety disorders or symptoms were present (de Azevedo Cardoso et al., 2014; Forand et al., 2011; Kashdan and Roberts, 2011; Rohde et al., 2001; Smits et al., 2012). With regard to treatment continuation, in the majority of CT studies, anxiety disorders (Forand et al., 2011; Kashdan and Roberts, 2011; Rohde et al., 2001; Schindler et al., 2013; Smits et al., 2009) and anxiety symptoms (Forand et al., 2011; Fournier et al., 2009; McEvoy and Nathan, 2007; Smits et al., 2012) did not affect treatment dropout, although one study reported higher dropout rates for individuals with a comorbid anxiety disorder (Arnow et al., 2007). For IPT, fewer findings on the impact of comorbid anxiety on MDD treatment outcome and completion are available. In contrast to CT, findings of these studies suggest an adverse effect of (lifetime) anxiety disorders and anxiety symptoms on MDD outcome (Brown et al., 1996; Frank et al., 2011, 2000; Young et al., 2006). In addition, one study reported higher dropout rates for individuals with lifetime anxiety disorders as compared to individuals without lifetime anxiety disorders (Brown et al., 1996). To date, there are no head-to-head comparisons of CT and IPT focusing on anxious depression, although one study showed that axis I disorders in general did not predict (differential) MDD treatment outcomes for CT and IPT (Carter et al., 2011).

A possible explanation for these mixed results is the use of different definitions to classify anxious depression (Ionescu et al., 2013). This concern is illustrated by a recent study that showed that the syndromal and dimensional definitions of anxious depression classify two different groups of individuals under the same "anxious depression" label (van der Veen et al., 2014). This lack of overlap is not surprising; the syndromal definition refers to two distinct disorders, while the dimensional criteria define a certain subtype of depression. These different conceptualizations of anxious depression are however a major concern for integrating the outcomes of previous studies into broader knowledge and translating findings to clinical practice. In addition, mixed results could be explained by small study samples and the different measures of anxiety disorders and anxiety symptoms. Anxiety disorders diagnoses are measured both lifetime and current, with different types of instruments. Furthermore, diagnosing a distinct anxiety disorder from an acute phase depression can be challenging. For anxiety symptoms, some studies used specific anxiety oriented instruments while others used the Anxiety/ Somatization Factor of the Hamilton Rating Scale for Depression ( Fava et al., 2000).

The aim of this study was to examine the (differential) effect of comorbid anxiety on the effectiveness and treatment continuation of CT and IPT for MDD in a head-to-head comparison. In order to confirm the assumption that the syndromal definition of anxious depression is different from the dimensional one, the impact of anxiety disorders, anxiety symptoms (i.e. generalized anxiety symptoms), and phobic anxiety symptoms (i.e. agoraphobic symptoms) was examined separately. Based on previous studies, we expected no adverse effect of comorbid anxiety on MDD treatment outcomes and completion for CT. Based on the limited research available for IPT, one could expect less favorable outcomes and higher dropout rates for individuals with comorbid anxiety disorders or symptoms treated with IPT.

\section{Method}

\subsection{Study design}

Data were collected in the context of a randomized controlled trial examining the effectiveness of CT and IPT for MDD. Individuals with a primary MDD diagnosis as confirmed with the Structured Clinical Interview for DSM-IV Axis I disorders (SCID-I, First et al., 1995) by trained clinicians were recruited from the mood disorders unit of the Maastricht Outpatient Mental Health Center (RIAGG Maastricht). Additional inclusion criteria were: internet access, an email address, and sufficient knowledge of the Dutch language. Exclusion criteria were a bipolar or chronic depression (current episode $>5$ years), elevated acute suicide risk, concomitant pharmacological or psychological treatment, drugs and alcohol abuse/dependence, and mental retardation (IQ < 80). A total of 1562 individuals were screened for eligibility. Of these 1562 individuals, 1191 did not meet the inclusion criteria (main reasons were the use of antidepressant medication $(n=362)$ or MDD not being the primary diagnosis $(n=434), 78$ patients met inclusion criteria but refused to participate, and 111 were excluded for other reasons. A total of 182 depressed outpatients were randomly allocated to CT ( $n=76)$, IPT ( $n=75)$, or a 2 -month waiting-list control condition followed by treatment of choice $(n=31)$. For the current analyses, we limited the sample to data of individuals randomized to the active conditions CT and IPT $(n=151)$ in the acute phase of therapy (month $0-7$ ) and a trial follow-up phase (month 7-12). The study was approved by the Medical Ethics Committee of Mastricht University Medical Center, written informed consent was obtained, and the study was registered at isrctn.com (identifier: ISRCTN 67561918). A detailed description about the study design and main outcomes are provided elsewhere (Lemmens et al., 2015, 2011).

\subsection{Treatments and therapists}

CT and IPT were carried out using the guidelines by Beck et al. (1979) for CT, and the guidelines by Klerman et al. (1984) for IPT. Participants received $16-20$ sessions of 45 min (17 sessions on average, $\mathrm{SD}=2.9$ ) by ten experienced licensed psychologist, psychotherapists, and psychiatrists (9.1 years of clinical experience on average, $\mathrm{SD}=5.4$, range 4-21 years). Therapists were already trained in the treatment modality that they delivered in the study, but received additional training $(2 \times 8 \mathrm{~h})$ by Steven Hollon (CT) and John Markowitz (IPT) prior to the start of the study, and delivered exclusively CT or IPT. Sessions were scheduled weekly and allowed to be less frequent planned towards the end of therapy. All sessions were videotaped and a random selection of 106 tapes were examined on treatment competence (i.e. quality of treatment) and adherence (i.e. therapy-specific behavior) by independent raters. Treatment competence was rated good to excellent using the Cognitive Therapy Scale for CT (Dobson et al., 1985, $M$ $=3.31, S D=0.93$ ) and the short version of the IPT Adherence and Quality Scale for IPT (Stuart, 2011, $M=3.50, S D=0.70$ ). The Collaborative Study Psychotherapy Rating Scale version 6 (Hollon et al., $1984,1988)$ indicated significant differences in therapy-specific behavior between CT and IPT with higher CT-specific behavior in CT as compared to IPT $(M=80.80, S D=25.64$ vs. $M=52.42, S D=13.00$ $t=7.23, p<0.001$ ), and higher IPT-specific behavior in IPT as compared to CT $(M=85.75, S D=23.22$ vs. $M=44.57, S D=15.06$, $t=10.79, p<0.001$ ) (Lemmens et al., 2015). Anxiety disorders, 
phobic anxiety symptoms and anxiety symptoms did not change quality of treatment or therapy-specific behavior of the therapists (results not shown, all p-values $>0.3$ ).

\subsection{Measures}

\subsubsection{Primary outcome}

The primary outcome, depression severity was measured with the Beck Depression Inventory, second edition (Beck et al., 1996), a 21-item self-report instrument. The total score was obtained by summing up the items, ranging between 0 and 63 , with a higher score indicated more severe depressive symptoms. The BDI-II has shown to be a strong screening measure for depression with high reliability and improved concurrent, content, and structural validity (Wang and Gorenstein, 2013). The BDI-II was repeatedly assessed across the treatment phase (BDI-II measures at the start of each therapy session), and the subsequent trial follow-up phase (BDI-II measures at 7, 8, 9, 10, 11 and 12 months).

\subsubsection{Comorbid anxiety}

Anxiety disorders were assessed at baseline using the results of the SCID-I (First et al., 1995). Prior to treatment, anxiety symptoms and phobic anxiety symptoms were measured with the Brief Symptom Inventory (BSI) anxiety subscale and the phobic anxiety subscale representing generalized anxiety symptoms and agoraphobic symptoms respectively. Higher scores indicated more severe symptoms (de Beurs, 2009; Derogatis and Melisaratos, 1983). The BSI is a 53-item self-report instrument that derived from the Symptom Checklist 90 Revised and has demonstrated to have good psychometric properties (De Beurs and Zitman, 2005; Derogatis and Melisaratos, 1983; Khalil et al., 2011). Therapists and participants were blind to the results of the BSI (anxiety symptoms), but not to the outcomes of the SCID-I assessment (anxiety disorders).

\subsection{Statistical analysis}

To examine pre-treatment characteristics, cutoffs for low and high (phobic) anxiety symptoms were used based on the Dutch outpatients population (de Beurs, 2009). Pre-treatment characteristics and (study and treatment ${ }^{\mathrm{I}}$ ) dropout rates of individuals with and without comorbid anxiety disorders, with low and high anxiety symptoms, and with low and high phobic anxiety symptoms were examined with $t$-tests and $\chi^{2-}$ tests where appropriate. To examine the differential impact of anxiety disorders, anxiety symptoms, and phobic anxiety symptoms on study and treatment dropout for CT and IPT, logistic regression models were applied. To confirm that the syndromal definition of anxious depression differs from the dimensional one, anxiety symptoms (standardized continuous score of the BSI anxiety subscale) and phobic anxiety symptoms (standardized continuous score of the BSI phobic anxiety subscale) were compared between individuals with and without an anxiety disorder ( $t$-test with Cohen's d). In addition, subgroups of individuals who met the criteria for the syndromal and dimensional definition were identified, and overlap between these groups was examined with a kappa statistics. ${ }^{\text {II }}$

To analyze the impact of anxiety disorders, anxiety symptoms (standardized continuous score of the BSI anxiety subscale) and phobic

\footnotetext{
${ }^{I}$ Treatment dropout was defined as discontinuation of treatment; study dropout was defined as discontinuation of study participation.

${ }^{\text {II }}$ For the dimensional criteria (MDD plus subthreshold anxiety symptoms) the BSI anxiety subscale was used and not the BSI phobic anxiety subscale. We choose this subscale since these items overlapped most with the somatic and physic anxiety subscales of the Hamilton Depression Rating Scale and Hamilton Anxiety Rating Scale that are often used to assess the dimensional criteria. Since guidelines for the appropriate thresholds of the BSI anxiety subscale for the dimensional definition were lacking, the analyses were repeated with different cutoffs based on a Dutch outpatient population (de Beurs, 2009).
}

anxiety symptoms (standardized continuous score of the BSI phobic anxiety subscale) on BDI-II change across treatment (measured at the start of each therapy session) and follow-up (measured at 7, 8, 9, 10, 11 and 12 months), mixed-effects models were used (Diggle et al., 2002). Analyses were intention-to-treat, using all available data of the 151 study participants. Since sessions were allowed to be scheduled in a flexible manner, for some participants, there was a slight overlap between treatment and trial follow-up phase (1 or 2 sessions). Due to this overlap, BDI-II change was modeled separately for each phase. The following fixed effects were included in the models: standardized BDI-II baseline scores (to adjust for different BDI-II scores prior to treatment (Lemmens et al., 2015)), time (treatment phase model: number of sessions; trial follow-up phase model: time in months), treatment (centered at CT $=-0.5$ or IPT $=0.5$ ), and a time-by-treatment interaction (difference between CT and IPT over time). Anxiety disorder diagnosis (centered at no diagnosis $=-0.5$ or one or more $=0.5$ ), anxiety symptoms (standardized continuous score of the BSI anxiety subscale) and phobic anxiety symptoms (standardized continuous score of the BSI phobic anxiety subscale) were subsequently added to these models together with their interactions with treatment, time and treatment-bytime. Since previous studies showed that anxiety could affect different types of depression change (i.e. early rapid change instead of overall change) (Forand and Derubeis, 2013; Forand et al., 2011), different transformations of time (linear quadratic, loglinear) were assessed for each model with fit indices and visual inspection. For the acute phase model with anxiety disorder diagnosis as a predictor, a curvilinear parametrization of time (linear and quadratic slope) was considered the best fit. All other models had the best fit with only linear slopes. For these linear models, the endpoint of time was coded as zero (treatment phase model: session 20; trial follow-up phase model: month 12). To reduce multicollinearity between the linear and quadratic slopes, time was centered midway for the curvilinear model (treatment phase model: session 10) (Forand et al., 2011). For all models, intercepts and slopes were allowed to be correlated and vary randomly over individuals. An autoregressive covariance structure for the residuals was modeled, with a correction for the irregularly spaced time lags between the sessions (Jones, 1993). Backwards elimination was applied when the anxiety-by-treatment-by-time-interaction was not significant $(\mathrm{p}>0.05)$.

For all models, we conducted a sensitivity analysis by subsequently adding the following variables measured at baseline to the models: therapist, demographics (age, gender, employment, level of education), clinical features (first or recurrent depression) and functionality (Work and Social Adjustment Scale (W\&SAS), Mundt et al., 2002), the RAND36 (van der Zee and Sanderman, 1993) and the EuroQol-6D (EQ-6D, EuroQol, 1990) for the EQ-5D).

\section{Results}

\subsection{Descriptive statistics}

Pre-treatment characteristics are shown in Table 1 . As described by Lemmens et al. (2015), the baseline EQ-5D and BDI-II were borderline significantly higher in CT as compared to IPT $(t=2.00, d f=148$, $p=0.05$ and $t=1.90, d f=149, p=0.06)$ for the complete sample. There were no significant differences between the two conditions in treatment $(\mathrm{n}=36$, CT $\mathrm{n}=20$, IPT $\mathrm{n}=16)$ and study $(\mathrm{n}=23$, CT $\mathrm{n}=20$, IPT $\mathrm{n}=16$ ) dropout.

\subsubsection{Anxiety disorders}

43 out of 151 individuals were diagnosed with one $(n=35 ; 23.2 \%$; CT $=19$, IPT $=16)$ or two $(n=8 ; 5.3 \%$; CT $=5$, IPT $=3)$ anxiety disorders. The number of individuals with anxiety disorders did not differ between the two conditions (CT $=24$, IPT $=19, \chi^{2}=0.72$, df $=1, p=0.40$ ). The most prevalent anxiety disorder was panic disorder $(n=18)$, followed by social phobia $(n=16)$, specific phobia $(n=7)$, 


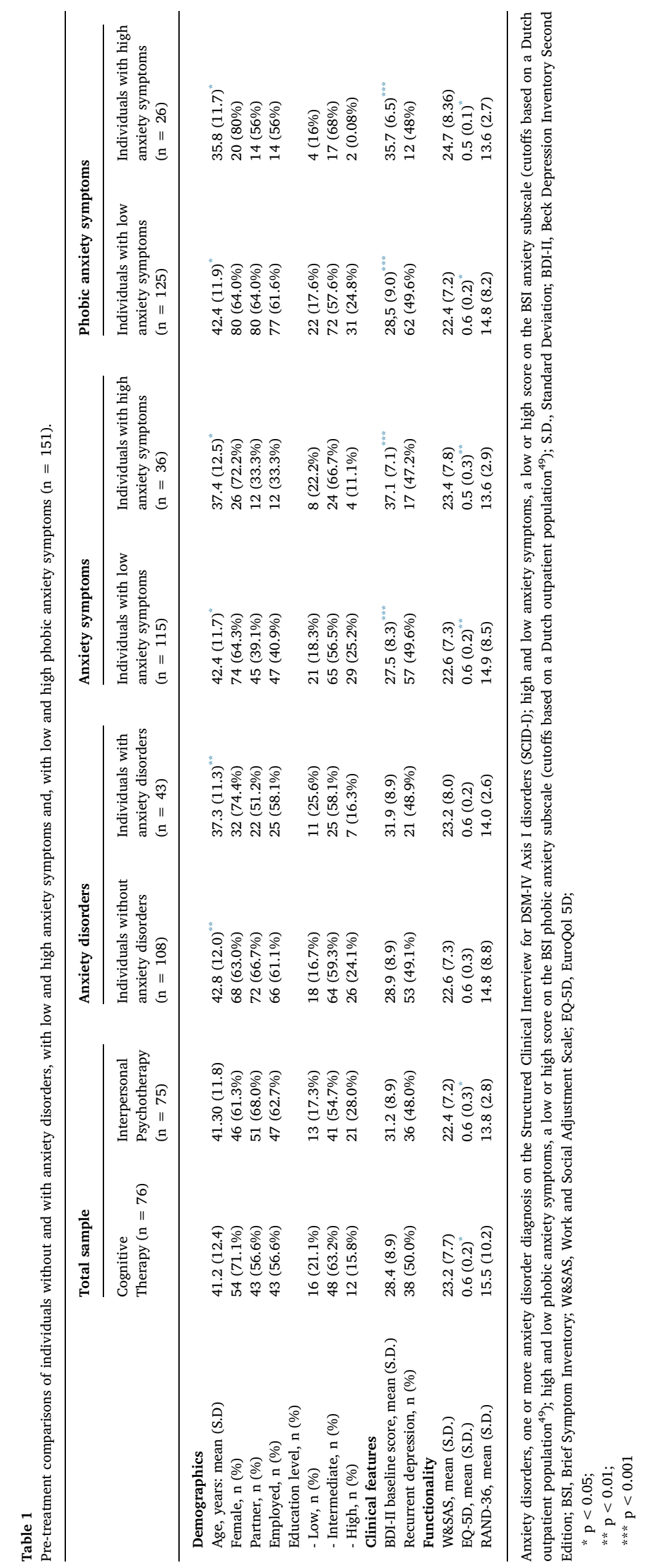


post-traumatic stress disorder $(n=6)$, generalized anxiety disorder $(n=2)$, agoraphobia without panic disorder $(n=1)$, obsessive compulsive disorder $(n=1)$ and anxiety disorder not otherwise specified $(n=1)$. As shown in Table 1 , individuals with a comorbid anxiety disorder were significantly younger compared to individuals without a comorbid anxiety disorder $(t=2.62$, df $=149, p=0.0098)$.

\subsubsection{Anxiety symptoms and phobic anxiety symptoms}

36 of 151 individuals scored above the 'high anxiety symptoms cutoff' (de Beurs, 2009) on the BSI anxiety subscale and the number of individuals with high anxiety symptoms did not significantly differ between CT and IPT (CT $=17$, IPT $=19, \chi 2=0.18$, $\mathrm{df}=1, p=0.67$ ). For the BSI phobic anxiety subscale, 26 of 151 individuals scored above the 'high phobic anxiety symptoms cutoff' (de Beurs, 2009) and appeared to be equally divided between CT and IPT as well (CT $=13$, IPT $=13, \chi^{2}=0.0014$, $\mathrm{df}=1, p=0.970$ ). As presented in Table 1 , participants with high anxiety symptoms and high phobic anxiety symptoms were significantly younger $(t=2.30$, $\mathrm{df}=149, p=0.03$ and $t=2.59$, df $=149, p=0.01$ ), had higher baseline depression severity $(t=-6.23, \quad \mathrm{df}=149, \quad p<0.001$ and $t=-3.88, \mathrm{df}=149$, $p=0.002$ ), and lower quality of life measured with the EQ-5D $(t=3.17, \mathrm{df}=148, p=0.002$ and $t=2.19$, $\mathrm{df}=148, p=0.03)$ as compared to individuals with low anxiety symptoms and low phobic anxiety symptoms respectively.

\subsection{Comparing the syndromal and dimensional definition of anxious depression}

Individuals with an anxiety disorder scored significantly higher on the BSI anxiety subscale as compared to individuals without an anxiety disorder $(M=1.58, S D=0.81$ vs. $M=1.29, S D=0.79, t=-2.0$, df $=149, p=0.05$, Cohen's $\mathrm{d}=-0.36$ ). In addition, scores on the BSI phobic anxiety subscale were higher for individuals with an anxiety disorder compared to individuals without an anxiety disorder $(M$ $=1.36, S D=0.81$ vs. $M=0.81, S D=0.71, t=-4.13$, df $=149$, $p=0.0001$, Cohen's $d=-0.74)$. However, when dividing the sample into subgroups of syndromal and dimensional defined anxious depression and non-anxious depression, little agreement was found between the syndromal and dimensional subgroups with kappa statistics ranging between -0.003 and 0.16 .

\subsection{The impact of anxiety disorders on BDI-II change and dropout}

Table 2 provides the estimates of the mixed-effect models examining the impact of anxiety disorders on BDI-II change for the treatment phase ( $0-7$ months) and the trial follow-up phase ( $7-12$ months). For the treatment phase model, there was a significant three way interaction between anxiety disorder status, condition and the quadratic time slope, indicating higher BDI-II scores for individuals with an anxiety disorder receiving IPT as compared to CT. This effect is illustrated by Fig. 1, where the raw means of the BDI-II scores are plotted and show a curvilinear unfavorable course for IPT as compared to the CT group. This differential effect was not found in the trial follow-up phase. Sensitivity analyses did not change these results.

For individuals with a comorbid anxiety disorder the proportion of treatment dropouts was significantly higher $(n=17,39.5 \%)$ as compared to individuals without a comorbid anxiety disorder $(n=19$, $\left.17.6 \%, \chi^{2}=8.16, \mathrm{df}=1, p=0.004\right)$, although this difference was not found for study dropouts ( $\chi 2=1.51$, df $=1, p=0.219$ ). As indicated by the non-significant treatment by anxiety disorder interactions in the logistic regression models, no differential effects between CT and IPT were found for both treatment $(\beta=0.67, p=0.409)$ and study $(\beta=$ $0.23, \mathrm{p}=0.807$ ) dropout.

\subsection{The impact of anxiety symptoms and phobic anxiety symptoms on BDI- II change and dropout}

Table 3 summarizes the effects of anxiety symptoms (standardized continuous score of the BSI anxiety subscale) and phobic anxiety symptoms (standardized continuous score of the BSI phobic anxiety subscale) on BDI-II change as estimated with separate linear mixedeffects models. Initially, there was no (differential) effect of anxiety symptoms on BDI-II change in both conditions during treatment and trial follow-up phase. However, after eliminating the anxiety symptoms $\mathrm{x}$ time $\mathrm{x}$ condition interaction from the treatment phase model, a significant anxiety symptoms $\mathrm{x}$ condition interaction appeared, indicating overall higher BDI-II scores for IPT compared to CT. Fig. 2 illustrates this lower order effect with mean BDI-II scores during the treatment phase. This effect was not found in the trial follow-up phase. Phobic anxiety did not affect BDI-II change and backwards elimination did not alter the lower order effects significantly. Sensitivity analyses did not

Table 2

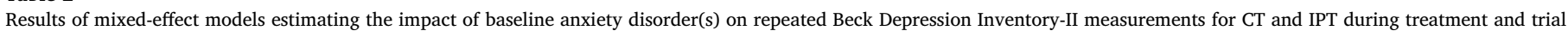
follow-up phase.

\begin{tabular}{|c|c|c|c|c|c|c|c|c|c|c|}
\hline & \multicolumn{5}{|c|}{$\begin{array}{l}\text { Treatment phase (BDI-II measurements at the start of each therapy } \\
\text { session) }\end{array}$} & \multicolumn{5}{|c|}{$\begin{array}{l}\text { Trial follow-up phase (BDI-II measurements at 7, 8, 9, 10, } 11 \text { and } 12 \\
\text { months) }\end{array}$} \\
\hline & \multicolumn{3}{|c|}{ Fixed effect } & \multicolumn{2}{|c|}{ Random effect } & \multicolumn{3}{|c|}{ Fixed effect } & \multicolumn{2}{|c|}{ Random effect } \\
\hline & $\beta$ & S.E. & $\mathrm{p}$ & Var. & SE & $\beta$ & S.E. & $\mathrm{p}$ & Var. & SE \\
\hline Intercept & 19.72 & 0.84 & $<0.001$ & 72.00 & 9.56 & 15.02 & 1.21 & $<0.001$ & 124.72 & 18.23 \\
\hline BDI-II baseline & 7.33 & 0.52 & $<0.001$ & & & 5.27 & 0.94 & $<0.001$ & & \\
\hline Condition & 3.31 & 1.69 & 0.051 & & & 2.33 & 2.44 & 0.340 & & \\
\hline Time & -0.83 & 0.08 & $<0.001$ & 0.43 & 0.09 & -0.02 & 0.16 & 0.913 & 0.12 & 0.10 \\
\hline Time $\times$ condition & 0.44 & 0.16 & 0.006 & & & 0.13 & 0.31 & 0.670 & & \\
\hline Time $^{2}$ & 0.001 & 0.001 & 0.838 & & & & & & & \\
\hline Time $^{2} \times$ condition & 0.01 & 0.01 & 0.435 & & & & & & & \\
\hline Anxiety Disorder (AD) & -0.19 & 1.69 & 0.912 & & & -1.18 & 2.45 & 0.629 & & \\
\hline $\mathrm{AD} \times$ condition & 3.93 & 3.37 & 0.243 & & & 1.60 & 4.85 & 0.741 & & \\
\hline $\mathrm{AD} \times$ time & -0.10 & 0.16 & 0.518 & & & -0.07 & 0.31 & 0.831 & & \\
\hline $\mathrm{AD} \times$ condition $\times$ time & 0.51 & 0.32 & 0.113 & & & -0.76 & 0.62 & 0.221 & & \\
\hline $\mathrm{AD} \times$ time $^{2}$ & 0.001 & 0.01 & 0.935 & & & & & & & \\
\hline $\mathrm{AD} \times$ condition $\times$ time $^{2}$ & 0.09 & 0.03 & 0.001 & & & & & & & \\
\hline
\end{tabular}

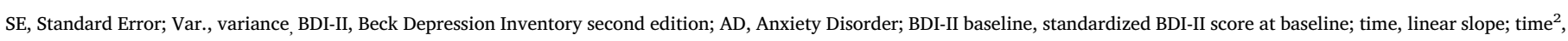
quadratic slope.

* model with a linear and a quadratic slope (best fit). Time is centered midway (at session 10).

** model with only a linear slope (best fit). The endpoint of time was coded as zero (at month 12). 
Cognitive Therapy

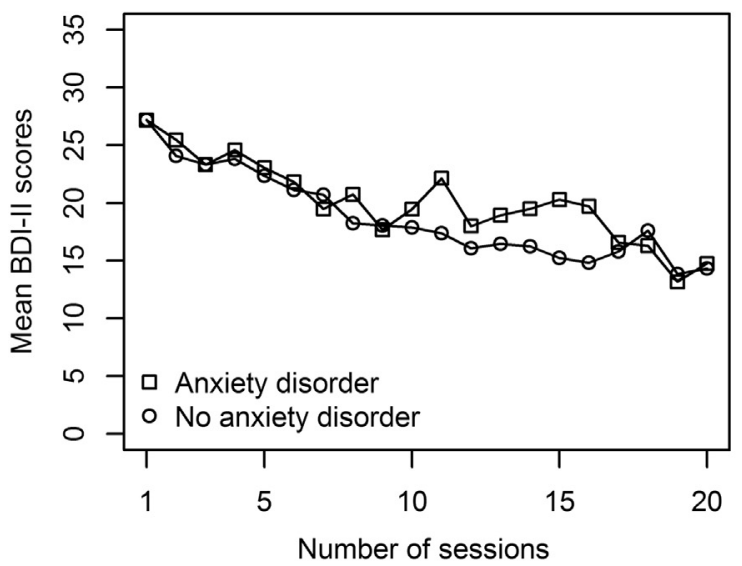

Interpersonal Psychotherapy

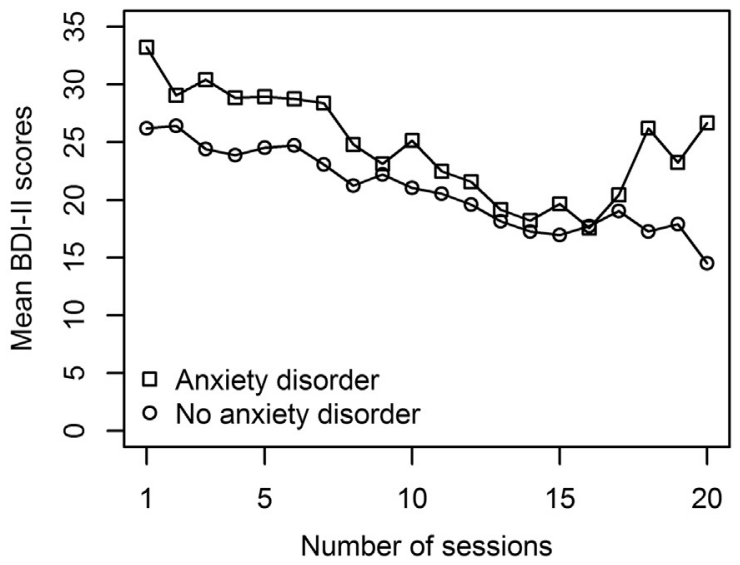

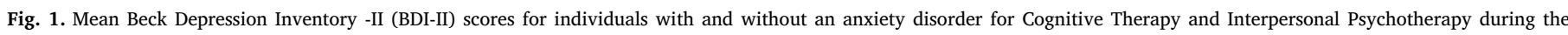
treatment phase. Data were available for 149, 142, 124, 89 and 25 individuals at session 1, 5, 10, 15 and 20 respectively (partly due to treatment termination).

change the results. Treatment dropout rates did not differ between individuals with low and high anxiety symptoms $(\chi 2=0.04$, df $=1$, $p=0.852$ ). However, there were significantly higher study dropout rates for individuals with high anxiety symptoms (27.8\%) as compared to low anxiety symptoms $(11.3 \%, \chi 2=5.76$, $\mathrm{df}=1, p=0.02)$. No differences in treatment and study dropout rates were found between individuals with low and high phobic anxiety symptoms $(\chi 2=2.01, \mathrm{df}$ $=1, p=0.16$ and $\chi 2=1.50$, df $=1, p=0.22$ ). As indicated by the non-significant treatment by anxiety symptoms interactions in the logistic regression models, no differential effects between CT and IPT were found for both treatment $(\beta=0.06, p=0.474)$ and study $(\beta=0.02, p=0.798)$ dropout. For phobic anxiety symptoms, nonsignificant interactions for treatment $(\beta=0.02, \mathrm{p}=0.837)$ and study $(\beta=-0.07, p=0.549)$ dropout were found as well.

\section{Discussion}

The main goal of the current study was to determine the influence of comorbid anxiety on the effectiveness and treatment completion of CT and IPT for MDD. Our most important findings were that, in the treatment phase, anxiety disorders and anxiety symptoms were associated with better depression change in CT as compared to IPT, and that individuals with anxiety disorders (but not anxiety symptoms) were more likely to dropout during both treatments.

The finding that anxiety disorders and anxiety symptoms had a less favorable impact on depression change for IPT as compared to CT in the treatment phase, was not completely unexpected. Although no previous head-to-head comparisons were available, comorbid anxiety have been found to negatively impact MDD outcome for IPT (Brown et al., 1996; Frank et al., 2011, 2000; Young et al., 2006), in contrast to the absence

Table 3

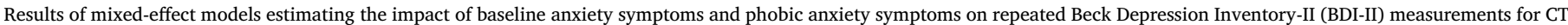
and IPT during treatment and trial follow-up phase.

\begin{tabular}{|c|c|c|c|c|c|c|c|c|c|c|}
\hline & \multicolumn{5}{|c|}{$\begin{array}{l}\text { Treatment phase (BDI-II measurements at the start of each therapy } \\
\text { session) }\end{array}$} & \multicolumn{5}{|c|}{$\begin{array}{l}\text { Trial follow-up phase (BDI-II measurements at 7, 8, 9, 10, } 11 \text { and } 12 \\
\text { months) }\end{array}$} \\
\hline & \multicolumn{3}{|c|}{ Fixed effect } & \multicolumn{2}{|c|}{ Random effect } & \multicolumn{3}{|c|}{ Fixed effect } & \multicolumn{2}{|c|}{ Random effect } \\
\hline & $\beta$ & S.E. & $\mathrm{p}$ & Var. & SE & $\beta$ & S.E. & $\mathrm{p}$ & Var. & SE \\
\hline Anxiety Symptoms (AS) & 0.89 & 1.38 & 0.519 & & & 1.37 & 1.28 & 0.164 & & \\
\hline Intercept & 11.54 & 1.30 & $<0.001$ & 205.13 & 31.42 & 15.25 & 1.06 & $<0.001$ & 123.18 & 18.00 \\
\hline BDI-II baseline & 6.45 & 0.65 & $<0.001$ & & & 3.86 & 1.16 & 0.001 & & \\
\hline Time & -0.81 & 0.07 & $<0.001$ & 0.44 & 0.09 & -0.003 & 0.13 & 0.998 & 0.12 & 0.09 \\
\hline Condition & 5.41 & 2.63 & 0.039 & & & 2.10 & 2.12 & 0.323 & & \\
\hline Time $\times$ condition & 0.34 & 0.14 & 0.013 & & & 0.36 & 0.27 & 0.179 & & \\
\hline AS $\times$ time & -0.027 & 0.07 & 0.691 & & & -0.19 & 0.14 & 0.164 & & \\
\hline AS $\times$ condition $^{*}$ & 2.30 & 1.04 & 0.028 & & & 0.12 & 1.84 & 0.946 & & \\
\hline Phobic Anxiety Symptoms (PAS) & 0.60 & 1.38 & 0.664 & & & -0.10 & 1.21 & 0.934 & & \\
\hline Intercept & 11.62 & 1.32 & $<0.001$ & 210.19 & 31.96 & 15.21 & 1.06 & $<0.001$ & 124.77 & 18.07 \\
\hline BDI-II baseline & 7.33 & 0.60 & $<0.001$ & & & 4.45 & 1.07 & $<0.001$ & & \\
\hline Time & -0.81 & 0.07 & $<0.001$ & 0.44 & 0.09 & -0.004 & 0.13 & 0.973 & 0.12 & 0.09 \\
\hline Condition & 5.32 & 2.64 & 0.044 & & & 2.17 & 2.13 & 0.309 & & \\
\hline Time $\times$ condition & 0.33 & 0.14 & 0.016 & & & 0.30 & 0.27 & 0.252 & & \\
\hline PAS $\times$ time & 0.03 & 0.07 & 0.721 & & & -0.37 & 0.14 & 0.007 & & \\
\hline PAS $\times$ condition & -0.45 & 2.71 & 0.868 & & & -2.23 & 2.17 & 0.303 & & \\
\hline PAS $\times$ condition $\times$ time & -0.12 & 0.14 & 0.406 & & & -0.42 & 0.27 & 0.121 & & \\
\hline
\end{tabular}

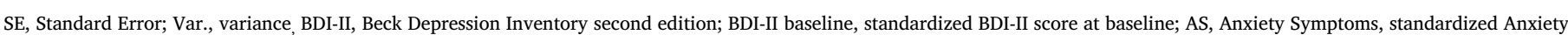

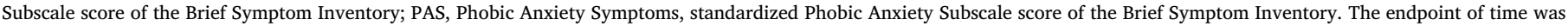
coded as zero (session 20 for the treatment phase model and month 12 for the trial follow-up phase model).

* Model with elimination of the anxiety-by-treatment-by-time-interaction: lower order effects appeared to be significant. 


\section{Cognitive Therapy}

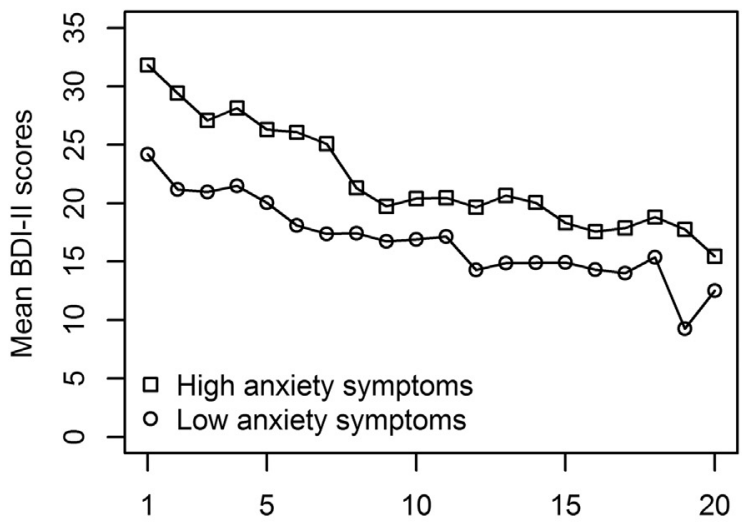

Number of sessions

\section{Interpersonal Psychotherapy}

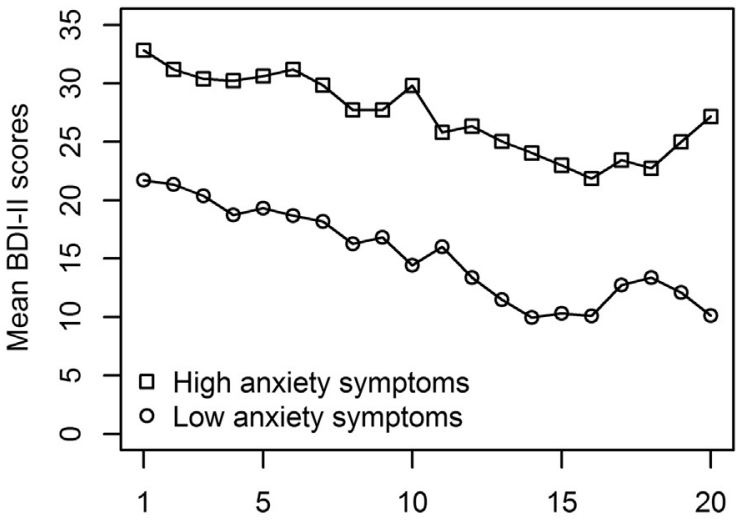

Number of sessions

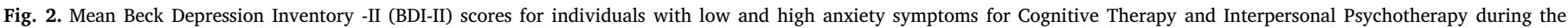
treatment phase. Data were available for 149, 142, 124, 89 and 25 individuals at session 1, 5, 10, 15 and 20 respectively (partly due to treatment termination).

of adverse effects of anxiety for CT (Brent et al., 1998; de Azevedo Cardoso et al., 2014; Forand and Derubeis, 2013; Forand et al., 2011; Fournier et al., 2009; Kashdan and Roberts, 2011; McEvoy and Nathan, 2007; Persons et al., 2006; Rohde et al., 2001; Smits et al., 2009). In addition, there is evidence that CT outperformed IPT in the treatment of panic disorder (Vos et al., 2012) and social anxiety disorder (Stangier et al., 2011). A possible explanation for these differences is the focus on exposure in CT through "in vivo" homework assignments. The moderating effect of anxiety however was not found across five months follow-up indicating no differential effects in the long term. A possible interpretation of these follow-up findings could be that the impact of IPT took longer to manifest as compared to CT, but is equally effective for anxious depression at the longer term. Similar temporal patterns and differences between CT and IPT were also found in two randomized controlled trials on bulimia nervosa. In these trials, CT appeared to be more effective than IPT in reducing symptoms at the end of therapy. However, these differences were not found during follow-up (Agras et al., 2000; Fairburn et al., 1993). Possibly, these temporal differences could reflect specific mechanisms of change of CT and IPT. To better understand the discrepancies between our treatment and follow-up phase outcomes, further CT versus IPT comparisons on anxious depression are needed with longer follow-up durations and the inclusion of possible mediating variables that could explain different mechanism of change.

The higher treatment dropout rates for individuals with comorbid anxiety disorders have been found in some (Arnow et al., 2007; Brown et al., 1996; Howland et al., 2009), but not all (Forand et al., 2011; Kashdan and Roberts, 2011; Rohde et al., 2001; Schindler et al., 2013; Smits et al., 2009) previous studies. One could explain these higher dropout rates as a form of avoidance behavior, a key feature of anxiety disorders (American Psychiatric Association, 2013). In contrast to our hypothesis, no differential effects of anxiety symptoms on dropout rates were found between CT and IPT.

In our study, we also found that the two different (syndromal and dimensional) definitions for anxious depression define two different groups of individuals. This is line with the results of a previous study (van der Veen et al., 2014) and further supported by the differences we found for pre-treatment depression severity and quality of life with a more severe clinical picture for individuals with the dimensional definition of anxious depression. As mentioned before, a plausible explanation for these differences is that the syndromal criteria identify two distinct disorders (MDD and anxiety disorder), while the dimensional criteria identify a more severe (anxious) subtype of MDD. Logically, one of the exclusion criteria for a DSM anxiety disorder is "not better accounted for by another mental disorder", so the anxiety cannot be part of the depression symptomatology. With the central position of anxiety symptoms in MDD (Ten Have et al., 2016), one could argue that anxious depression should only be defined with dimensional criteria (Ionescu et al., 2013; Silverstone and von Studnitz, 2003), which is also in accordance to the newly proposed DSM-5 'anxious distress specifier' for the diagnosis of MDD (American Psychiatric Association, 2013).

To our knowledge this is the first study that examined anxious depression determined by both syndromal and dimensional criteria in a head-to-head comparison of CT and IPT. Other strengths of our study are the random allocation, the relative large sample size, and the multiple assessments of depressive symptoms that were analyzed with state of the art mixed models (Lemmens et al., 2015). The current study also has some limitations. First, no inter-reliability data for the SCID-I was collected and patients and therapist were not blind for the results of the SCID-I. Therapists were blind for the results of the BSI anxiety subscale and phobic anxiety subscale. Although therapists were not instructed to adapt treatments if comorbid anxiety was present, this knowledge could have altered treatment strategies. However, our competence and adherence check revealed no impact of comorbid anxiety on quality of treatment or therapy specific behavior. Second, our treatment and the trial follow-up phase models slightly overlap since a few participants had one or two therapy session during the trial followup phase. Third, although the overall dropout rates of the current study were low, individuals with anxiety disorders had relatively high dropout rates. Due to the use of mixed models, this is unlikely to affect our findings drastically. However, we think that larger sample sizes of individuals with comorbid anxiety disorders are warranted. In addition, the presence of these high dropout rates is an informative and clinically relevant finding.

The findings of this study have significant clinical implications. Most importantly, the presence of anxiety disorders and anxiety symptoms should be considered when selecting an effective psychotherapy for a depressed individual. Based on these results, a preference to CT over IPT is justifiable. Selecting the best treatment option for a given individual, is in line with the "personalized medicine" movement in health care research and practice today (Simon and Perlis, 2010). If IPT is the first choice of treatment for other reasons, clinicians could also consider to use a modified version of IPT that includes cognitive-behavioral strategies to target symptoms of panic, anxiety and avoidance that interfere with interpersonal problem solving (Cyranowski et al., 2005). Another important clinical implication is that the patient's adherence to therapy should be carefully monitored when a comorbid anxiety disorder is diagnosed. With the assessment of other 
predictors of treatment drop-out (e.g. ethnic minority status, younger age, lower income, low motivation for change, poor therapeutic alliance, low treatment credibility and failure to improve early in treatment (Arnow et al., 2007; Cooper and Conklin, 2015; Schindler et al., 2013; Taylor et al., 2012)), individual risks for dropout should be estimated, and specific interventions to prevent dropout can be considered, for example motivational interviewing techniques (Miller and Rollnick, 2002). Another issue is that based on our finding that anxiety symptoms are associated with more severe depressive symptomatology and lower quality of life prior to treatment, a clinician can be confronted with significant levels of distress when anxiety symptoms are present. To deal with this more severe clinical picture, combination therapy (psychotherapy and pharmacotherapy) can be considered, since it has been formulated as the treatment of choice for severe depression (NICE, 2009). Finally, when depression and anxiety co-occur, transdiagnostic approaches for both CT and IPT focussing both on depressive and anxiety symptoms show promising results (Newby et al., 2015; Wright et al., 2014).

\section{Acknowledgements}

We would like to acknowledge the contribution of participants and therapists at RIAGG Maastricht. Furthermore, we thank Annie Raven and Annie Hendriks for their assistance during the study.

\section{Funding}

This research was funded by the research institute of Experimental Psychopathology (EPP), the Netherlands, and the Academic Community Mental Health Centre (RIAGG Maastricht) in Maastricht, the Netherlands. Both institutes had no involvement in the collection, analysis and interpretation of the data or in the writing of this article and decision to submit this article for publication.

\section{Contributors}

AA, MH, FP designed the study and wrote the protocol. Author SB managed the literature searches and analyses. Author SB undertook the statistical analysis, and author SB wrote the first draft of the manuscript. All authors (AA, MH, FP, LL, SB) contributed to and have approved the final manuscript

\section{Conflict of interest}

All authors declare that they have no competing interests.

\section{References}

Agras, W.S., Walsh, B.T., Fairburn, C.G., Wilson, G.T., Kraemer, H.C., 2000. A multicenter comparison of cognitive-behavioral therapy and interpersonal psychotherapy for bulimia nervosa. Arch. Gen. Psychiatry 57, 459-466.

American Psychiatric Association, 2013. Diagnostic and statistical manual of mental disorders (5th ed.), Washington DC.

Arnow, B.A., Blasey, C., Manber, R., Constantino, M.J., Markowitz, J.C., Klein, D.N. Thase, M.E., Kocsis, J.H., Rush, A.J., 2007. Dropouts versus completers among chronically depressed outpatients. J. Affect Disord. 97, 197-202.

Beck, A.T., Rush, A.J., Shaw, B.F., Emery, G., 1979. Cognitive Therapy of Depression. Guilford Press, New York.

Beck, A.T., Steer, R., Brown, G.K., 1996. Beck Depression Inventory II: Manual. Harcourt Brace, Boston.

Brent, D.A., Kolko, D.J., Birmaher, B., Baugher, M., Bridge, J., Roth, C., Holder, D., 1998. Predictors of treatment efficacy in a clinical trial of three psychosocial treatments for adolescent depression. J. Am. Acad. Child Adolesc. Psychiatry 37, 906-914.

Brown, C., Schulberg, H.C., Madonia, M.J., Shear, M.K., Houck, P.R., 1996. Treatment outcomes for primary care patients with major depression and lifetime anxiety disorders. Am. J. Psychiatry 153, 1293-1300.

Carter, J.D., Luty, S.E., McKenzie, J.M., Mulder, R.T., Frampton, C.M., Joyce, P.R., 2011. Patient predictors of response to cognitive behaviour therapy and interpersonal psychotherapy in a randomised clinical trial for depression. J. Affect Disord. 128, 252-261.

Cooper, A.A., Conklin, L.R., 2015. Dropout from individual psychotherapy for major depression: a meta-analysis of randomized clinical trials. Clin. Psychol. Rev. 40, 57-65.

Cyranowski, J.M., Frank, E., Shear, M.K., Swartz, H., Fagiolini, A., Scott, J., Kupfer, D.J., 2005. Interpersonal psychotherapy for depression with panic spectrum symptoms: a pilot study. Depress. Anxiety 21, 140-142.

Davidson, J.R., Meoni, P., Haudiquet, V., Cantillon, M., Hackett, D., 2002. Achieving remission with venlafaxine and fluoxetine in major depression: its relationship to anxiety symptoms. Depress Anxiety 16, 4-13.

de Azevedo Cardoso, T., Mondin, T.C., Spessato, B.C., de Avila Quevedo, L., de Mattos Souza, L.D., da Silva, R.A., Jansen, K., 2014. The impact of anxious symptoms in the remission of depressive symptoms in a clinical trial for depression: follow-up of six months. J. Affect Disord. 168, 331-336.

de Beurs, E., 2009. Brief Symptom Inventory, handleiding addendum.

De Beurs, E., Zitman, F., 2005. De Brief Symptom Inventory (BSI). De betrouwbaarheid en validiteit van een handzaam alternatief voor de SCL-90. Leiden: Leids universitair medisch centrum.

Derogatis, L.R., Melisaratos, N., 1983. The Brief Symptom Inventory: an introductory report. Psychol. Med 13, 595-605.

Diggle, P., Heagerty, P., Liang, K., Zeger, S., 2002. Analysis of Longitudinal Data (Oxford Statistical Science Series), 2nd ed. Oxford University Press, Oxford.

Dobson, K.S., Shaw, B.F., Vallis, T.M., 1985. Reliability of a measure of the quality of cognitive therapy. Br. J. Clin. Psychol. 24, 295-300.

EuroQol, G., 1990. EuroQol-a new facility for the measurement of health-related quality of life. Health Policy 16, 199-208.

Fairburn, C.G., Jones, R., Peveler, R.C., Hope, R., O'connor, M., 1993. Psychotherapy and bulimia nervosa: longer-term effects of interpersonal psychotherapy, behavior therapy, and cognitive behavior therapy. Arch. Gen. Psychiatry 50, 419-428.

Fava, M., Alpert, J.E., Carmin, C.N., Wisniewski, S.R., Trivedi, M.H., Biggs, M.M., ShoresWilson, K., Morgan, D., Schwartz, T., Balasubramani, G.K., Rush, A.J., 2004. Clinical correlates and symptom patterns of anxious depression among patients with major depressive disorder in STAR*D. Psychol. Med. 34, 1299-1308.

Fava, M., Rosenbaum, J.F., Hoog, S.L., Tepner, R.G., Kopp, J.B., Nilsson, M.E., 2000. Fluoxetine versus sertraline and paroxetine in major depression: tolerability and efficacy in anxious depression. J. Affect. Disord. 59, 119-126.

Fava, M., Rush, A.J., Alpert, J.E., Balasubramani, G.K., Wisniewski, S.R., Carmin, C.N., Biggs, M.M., Zisook, S., Leuchter, A., Howland, R., Warden, D., Trivedi, M.H., 2008. Difference in treatment outcome in outpatients with anxious versus nonanxious depression: a STAR*D report. Am. J. Psychiatry 165, 342-351.

Fawcett, J., Scheftner, W.A., Fogg, L., Clark, D.C., Young, M.A., Hedeker, D., Gibbons, R., 1990. Time-related predictors of suicide in major affective disorder. Am. J. Psychiatry 147, 1189-1194.

First, M., Spitzer, R., Gibbon, M., Williams, J., 1995. Structured Clinical Interview for DSM-IV Axis I Disorders (SCID-I). Biometrics Research Department. New York State Psychiatric Institute., New York.

Flint, A.J., Rifat, S.L., 1997. Anxious depression in elderly patients. Response to antidepressant treatment. Am. J. Geriatr. Psychiatry 5, 107-115.

Forand, N.R., Derubeis, R.J., 2013. Pretreatment anxiety predicts patterns of change in cognitive behavioral therapy and medications for depression. J. Consult Clin. Psychol. 81, 774-782.

Forand, N.R., Gunthert, K.C., Cohen, L.H., Butler, A.C., Beck, J.S., 2011. Preliminary evidence that anxiety is associated with accelerated response in cognitive therapy for depression. Cogn. Ther. Res. 35, 151-160.

Fournier, J.C., DeRubeis, R.J., Shelton, R.C., Hollon, S.D., Amsterdam, J.D., Gallop, R., 2009. Prediction of response to medication and cognitive therapy in the treatment of moderate to severe depression. J. Consult. Clin. Psychol. 77, 775-787.

Frank, E., Cassano, G.B., Rucci, P., Thompson, W.K., Kraemer, H.C., Fagiolini, A., Maggi, L., Kupfer, D.J., Shear, M.K., Houck, P.R., Calugi, S., Grochocinski, V.J., Scocco, P., Buttenfield, J., Forgione, R.N., 2011. Predictors and moderators of time to remission of major depression with interpersonal psychotherapy and SSRI pharmacotherapy. Psychol. Med. 41, 151-162.

Frank, E., Shear, M.K., Rucci, P., Cyranowski, J.M., Endicott, J., Fagiolini, A., Grochocinski, V.J., Houck, P., Kupfer, D.J., Maser, J.D., Cassano, G.B., 2000. Influence of panic-agoraphobic spectrum symptoms on treatment response in patients with recurrent major depression. Am. J. Psychiatry 157, 1101-1107.

Hollon, S.D., Evans, M.D., Auerbach, A., DeRubeis, R.J., Elkin, I., Lowery, A., Kriss, M., Grove, W., Tuason, V.B., Piasecki, J., 1988. Development of a system for rating therapies for depression: differentiating cognitive therapy, interpersonal psychotherapy, and clinical management pharmacotherapy. (unpublished manuscript).

Hollon, S.D., Waskow, I.E., Evans, M., Lowery, H.A., 1984. Systems for Rating Therapies for Depression. Annual Convention of the American Psychiatric Association, Los Angeles, CA.

Howland, R.H., Rush, A.J., Wisniewski, S.R., Trivedi, M.H., Warden, D., Fava, M., Davis, L.L., Balasubramani, G.K., McGrath, P.J., Berman, S.R., 2009. Concurrent anxiety and substance use disorders among outpatients with major depression: clinical features and effect on treatment outcome. Drug Alcohol Depend. 99, 248-260.

Ionescu, D.F., Niciu, M.J., Henter, I.D., Zarate, C.A., 2013. Defining anxious depression: a review of the literature. CNS Spectr. 18, 252-260.

Joffe, R.T., Bagby, R.M., Levitt, A., 1993. Anxious and nonanxious depression. Am. J. Psychiatry 150, 1257-1258.

Jones, R.H., 1993. Longitudinal Data with Serial Correlation: A State-Space Approach (Chapman \& Hall/CRC Monographs on Statistics \& Applied Probability), 1st edition ed. Chapman \& Hall.

Kashdan, T.B., Roberts, J.E., 2011. Comorbid social anxiety disorder in clients with depressive disorders: predicting changes in depressive symptoms, therapeutic relationships, and focus of attention in group treatment. Behav. Res Ther. 49, 875-884.

Khalil, A.A., Hall, L.A., Moser, D.K., Lennie, T.A., Frazier, S.K., 2011. The psychometric 
properties of the Brief Symptom Inventory depression and anxiety subscales in patients with heart failure and with or without renal dysfunction. Arch. Psychiatr. Nurs. 25, 419-429.

Klerman, G.L., Weissman, M.M., Rounsaville, B.J., Chevron, E.S., 1984. Interpersona Psychotherapy for Depression. Basis Books, New York.

Lee, T.S., Nkouibert Assam, P., Gersing, K.R., Chan, E., Burchett, B.M., Sim, K., Feng, L., Krishnan, K.R., Rush, A.J., 2012. The effectiveness of antidepressant monotherapy in a naturalistic outpatient setting. Prim. Care Companion CNS Disord. 14.

Lemmens, L.H., Arntz, A., Peeters, F., Hollon, S.D., Roefs, A., Huibers, M.J., 2015. Clinical effectiveness of cognitive therapy v. interpersonal psychotherapy for depression: results of a randomized controlled trial. Psychol. Med. 45, 2095-2110.

Lemmens, L.H., Arntz, A., Peeters, F.P., Hollon, S.D., Roefs, A., Huibers, M.J., 2011 Effectiveness, relapse prevention and mechanisms of change of cognitive therapy vs. interpersonal therapy for depression: study protocol for a randomised controlled trial. Trials 12, 150.

McEvoy, P.M., Nathan, P., 2007. Effectiveness of cognitive behavior therapy for diagnostically heterogeneous groups: a benchmarking study. J. Consult Clin. Psychol. 75, 344-350.

Miller, W.R., Rollnick, S., 2002. Motivational Interviewing: Preparing People for Change, 2nd ed. Guilford, New York.

Mundt, J.C., Marks, I.M., Shear, M.K., Greist, J.H., 2002. The Work and Social Adjustment Scale: a simple measure of impairment in functioning. Br. J. Psychiatry 180, 461-464.

National Institute for Health and Care Excellence, 2009. Depression in adults: recognition and management.

Nelson, J.C., 2010. Anxiety does not predict response to duloxetine in major depression: results of a pooled analysis of individual patient data from 11 placebo-controlled trials. Depress. Anxiety 27, 12-18.

Newby, J.M., McKinnon, A., Kuyken, W., Gilbody, S., Dalgleish, T., 2015. Systematic review and meta-analysis of transdiagnostic psychological treatments for anxiety and depressive disorders in adulthood. Clin. Psychol. Rev. 40, 91-110.

Papakostas, G.I., McGrath, P., Stewart, J., Charles, D., Chen, Y., Mischoulon, D., Dording, C., Fava, M., 2008. Psychic and somatic anxiety symptoms as predictors of response to fluoxetine in major depressive disorder. Psychiatry Res. 161, 116-120.

Penninx, B.W., Nolen, W.A., Lamers, F., Zitman, F.G., Smit, J.H., Spinhoven, P., Cuijpers, P., de Jong, P.J., van Marwijk, H.W., van der Meer, K., Verhaak, P., Laurant, M.G., de Graaf, R., Hoogendijk, W.J., van der Wee, N., Ormel, J., van Dyck, R., Beekman, A.T., 2011. Two-year course of depressive and anxiety disorders: results from the Netherlands Study of Depression and Anxiety (NESDA). J. Affect. Disord. 133, 76-85.

Persons, J.B., Roberts, N.A., Zalecki, C.A., Brechwald, W.A., 2006. Naturalistic outcome of case formulation-driven cognitive-behavior therapy for anxious depressed outpatients. Behav. Res. Ther. 44, 1041-1051.

Pfeiffer, P.N., Ganoczy, D., Ilgen, M., Zivin, K., Valenstein, M., 2009. Comorbid anxiety as a suicide risk factor among depressed veterans. Depress. Anxiety 26, 752-757.

Rao, S., Zisook, S., 2009. Anxious depression: clinical features and treatment. Curr. Psychiatry Rep. 11, 429-436.

Rohde, P., Clarke, G.N., Lewinsohn, P.M., Seeley, J.R., Kaufman, N.K., 2001. Impact of comorbidity on a cognitive-behavioral group treatment for adolescent depression. J. Am. Acad. Child Adolesc. Psychiatry 40, 795-802.

Russell, J.M., Koran, L.M., Rush, J., Hirschfeld, R.M., Harrison, W., Friedman, E.S., Davis,
S., Keller, M., 2001. Effect of concurrent anxiety on response to sertraline and imipramine in patients with chronic depression. Depress. Anxiety 13, 18-27.

Schindler, A., Hiller, W., Witthoft, M., 2013. What predicts outcome, response, and dropout in CBT of depressive adults? A naturalistic study. Behav. Cogn. Psychother. 41, 365-370.

Silverstone, P.H., von Studnitz, E., 2003. Defining anxious depression: going beyond comorbidity. Can. J. Psychiatry 48, 675-680.

Simon, G.E., Perlis, R.H., 2010. Personalized medicine for depression: can we match patients with treatments? Am. J. Psychiatry 167, 1445-1455.

Smits, J.A., Minhajuddin, A., Jarrett, R.B., 2009. Cognitive therapy for depressed adults with comorbid social phobia. J. Affect. Disord. 114, 271-278.

Smits, J.A., Minhajuddin, A., Thase, M.E., Jarrett, R.B., 2012. Outcomes of acute phase cognitive therapy in outpatients with anxious versus nonanxious depression. Psychother. Psychosom. 81, 153-160.

Stangier, U., Schramm, E., Heidenreich, T., Berger, M., Clark, D.M., 2011. Cognitive therapy vs interpersonal psychotherapy in social anxiety disorder: a randomized controlled trial. Arch. Gen. Psychiatry 68, 692-700.

Stuart, S., 2011. IPT Adherence and Quality Scale. In: Interpersonal Psychotherapy Institute, Iowa (unpublished manuscript).

Taylor, S., Abramowitz, J.S., McKay, D., 2012. Non-adherence and non-response in the treatment of anxiety disorders. J. Anxiety Disord. 26, 583-589.

Ten Have, M., Lamers, F., Wardenaar, K., Beekman, A., de Jonge, P., van Dorsselaer, S. Tuithof, M., Kleinjan, M., de Graaf, R., 2016. The identification of symptom-based subtypes of depression: a nationally representative cohort study. J. Affect. Disord. 190, 395-406.

Tollefson, G.D., Holman, S.L., Sayler, M.E., Potvin, J.H., 1994. Fluoxetine, placebo, and tricyclic antidepressants in major depression with and without anxious features. J. Clin. Psychiatry 55, 50-59.

van der Veen, D.C., Comijs, H.C., van Zelst, W.H., Schoevers, R.A., Oude Voshaar, R.C., 2014. Defining anxious depression in later life: a scaring heterogeneity in results. Am. J. Geriatr. Psychiatry 22, 1375-1378.

van der Zee, K.I., Sanderman, R., 1993. Het meten van de algemene gezondheidstoestand met de RAND-36: een handleiding. Noordelijk Centrum voor Gezondheidsvraagstukken, Groningen.

Vos, S.P., Huibers, M.J., Diels, L., Arntz, A., 2012. A randomized clinical trial of cognitive behavioral therapy and interpersonal psychotherapy for panic disorder with agoraphobia. Psychol. Med. 42, 2661-2672.

Wang, Y.-P., Gorenstein, C., 2013. Psychometric properties of the Beck Depression Inventory-II: a comprehensive review. Rev. Bras. De. Psiquiatr. 35, 416-431.

Wiethoff, K., Bauer, M., Baghai, T.C., Moller, H.J., Fisher, R., Hollinde, D., Kiermeir, J., Hauth, I., Laux, G., Cordes, J., Brieger, P., Kronmuller, K.T., Zeiler, J., Adli, M., 2010. Prevalence and treatment outcome in anxious versus nonanxious depression: results from the German Algorithm Project. J. Clin. Psychiatry 71, 1047-1054.

Wright, A.G., Hallquist, M.N., Swartz, H.A., Frank, E., Cyranowski, J.M., 2014. Treating co-occurring depression and anxiety: modeling the dynamics of psychopathology and psychotherapy using the time-varying effect model. J. Consult Clin. Psychol. 82, 839-853.

Young, J.F., Mufson, L., Davies, M., 2006. Impact of comorbid anxiety in an effectiveness study of interpersonal psychotherapy for depressed adolescents. J. Am. Acad. Child Adolesc. Psychiatry 45, 904-912. 